\title{
Autologous OFA-iLRP RNA-Transfected Dendritic Cell Vaccine
}

National Cancer Institute

\section{Source}

National Cancer Institute. Autologous OFA-iLRP RNA-Transfected Dendritic Cell Vaccine.

NCI Thesaurus. Code C78830.

A cancer vaccine consisting of autologous, mature monocyte-derived dendritic cells (DCs) transfected with oncofetal antigen immature laminin receptor protein (OFA-iLRP) RNA, with potential antineoplastic activity. Upon administration, DCs in the OFA-iLRP RNA-transfected autologous dendritic cell vaccine express, process, and present OFAiLRP to the host immune system, which may mount a potent cytotoxic T-cell (CTL) response against OFA-iLRP-expressing tumor cells. As a highly conserved protein, OFAiLRP is preferentially expressed in fetal tissues and in many types of cancer, including hematopoietic malignancies, but is not detectable in normal differentiated adult cells. 